\title{
LA SENTENCIA DE LA HAYA CONTRA EL MURO DE CISJORDANIA EN LOS MEDIOS DE COMUNICACIÓN ESPAÑOLES
}

\author{
Clara $M^{a}$ Thomas de Antonio \\ Universidad de Sevilla
}

\begin{abstract}
RESUMEN
Este articulo analiza el modo en que los principales medios de comunicación españoles reflejan la sentencia del Tribunal Internacional de la Haya del 9 de julio de 2004 condenando la construcción del Muro israeli en Cisjordania, asi como las circunstancias en que se produce dicha sentencia.
\end{abstract}

Palabras clave: Palestina, el Muro, Cisjordania, Prensa española, Tribunal Internacional de la Haya.

ABSTRACT

This article analyzes the way in which the most important Spanish media reflects the sentence of the International Court of The Hague of 9 July 2004 condemning the erection of de Israeli Wall at the West Bank and the circumstances in which this sentence occurs.

Keywords: Palestine, The Wall, West Bank, Spanish Press, International Court of the Hague.

El Estado de Israel no ha dejado de dar pasos para hacer realidad el proyecto sionista, iniciado en 1882, de instalarse en Palestina. Para ello tenía que "desarabizar Palestina y judaizarla", y lo ha ido haciendo de diversos modos, todos ellos encaminados a hacer imposible la vida cotidiana de los palestinos en Cisjordania y Gaza -los Territorios Ocupados (TTOO)- con el objetivo último de echarlos de Palestina. Así Israel los somete a una humillación cotidiana, utiliza la violencia de forma sistemática contra ellos, oculta los esfuerzos que éstos hacen por vertebrar una sociedad civil sana, o intenta enfrentarlos entre sí $^{1}$. Y la política informativa israelí ${ }^{2}$,

\footnotetext{
1 Joss Dray y Denis Sieffert (2004) aportan muchos datos al respecto: en 1994, tras los acuerdos de Oslo, Rabin no apoyó a Arafat para controlar la violencia y cerró las fronteras de Gaza y Cisjordania con Israel, donde trabajaban muchos palestinos, castigando así a todo ese pueblo y estimulando el apoyo a los fedayines, según reconoce algún negociador israelí (p. 89); en 1997 y 1998 Arafat reprimió con eficacia a los grupos violentos palestinos, como reconocían algunos mandos israelíes (p. 88); en las negociaciones del 2000 y de 2001, Arafat se enfrentaba a un dilema, pues "la paz de los bantustanes en ningún caso podía convertirse en la paz de los palestinos. Y quien la hubiera ratificado, se habría deslegitimado ante los suyos” (p.
} 
centrada en transmitir la imagen de un "terrorismo" palestino contra el que tiene derecho a defenderse, constituye un pilar importante para ocultar esas tácticas y justificar su permanente conculcación de los más elementales derechos humanos del pueblo palestino y de la legalidad internacional.

Pero tal vez la política más eficaz de Israel para apoderarse de la Palestina histórica es la de los hechos consumados, sobre todo en lo referente a la ocupación de la tierra, que es la base física imprescindible para que se pueda establecer un Estado Palestino viable. Y el último hecho más destacado para ocupar tierra palestina es la construcción del Muro de Cisjordania.

\section{EL MURO, ANEXIÓN DE FACTO DE TIERRA PALESTINA}

La ocupación de Palestina comenzó con la compra de tierras por organizaciones sionistas para instalar en ellas a los inmigrantes judíos y dejar en paro a los campesinos palestinos. Luego, con la Partición de Palestina en 1947, la ONU le otorgó a Israel el $56 \%$ de la tierra, proporción que Israel amplió hasta el 78\% durante la guerra de 1948-49. Y la ocupación del resto de Palestina (Gaza y Cisjordania) la consumó en la Guerra de los Seis Días de junio de 1967.

La ocupación de ese $78 \%$, es decir, toda Palestina salvo Gaza y Cisjordania, quedó sancionada por los propios palestinos en Argel, en noviembre de 1988, al aceptar el derecho a la existencia del Estado de Israel. Luego, en las distintas fases del "procesos de paz", Israel ha intentado seguir legitimando su apropiación de la tierra en los TTOO, mientras ocupaba de hecho parte de ellos implantando allí gran número de colonias. Luego, en el verano de 2002, emprendió la construcción del Muro de Cisjordania, sobrepasando las fronteras de la línea verde de 1967 admitidas por la comunidad internacional. Con ese Muro pretende arrebatarles, por medio de los

83); y en 2001, ante las respuestas camicaces a los asesinatos selectivos de Israel, Arafat mandó detener a los responsables de los atentados, lo que le colocaba ante el dilema deseado por Israel: "ser considerado un traidor por lo suyos o un mentiroso por la comunidad internacional” (p. 87-88).

Son reveladoras en este sentido las opiniones del psiquiatra palestino Eyad el-Sarraj, director del centro de Salud Mental de Gaza. En "Descansen en paz" (2004), señala con pena que Sharon sabe cómo dividir a los palestinos, y muestra de ello es el proyecto de abandonar Gaza para demostrar que los palestinos son incapaces de vivir en paz: "Parece que Sharon va a convertir Gaza en un cenagal donde los líderes de las milicias se maten unos a otros (...). Está dispuesto a enviar más y más armas a cada una de las facciones para cumplir con esta misión. Y en el momento en el que cualquiera de ellos suponga una amenaza para Israel, enviará un phantom y misiles para eliminarle a él y a su familia (...). Sharon nos ha estudiado y nos ha comprendido, y actúa en consecuencia". Por desgracia, estos enfrentamientos internos se han producido en varias semanas de 2006 y 2007.

2 Dray y Sieffert (2004) analizan acertadamente los mecanismos de la propaganda israelí para manipular la información (ver nota 3). 
hechos consumados, otro gran bocado de tierra y hacer inviable un futuro Estado Palestino, camuflándolo de nuevo con el pretexto de la seguridad y el derecho a la autodefensa.

Ya en 2002, el "nuevo historiador" israelí Ilan Pappé comentaba las nefasta consecuencias de construir un "Muro en el corazón de Palestina": La idea del Muro fue propuesta como un "plan de paz" por los laboristas en 1992, con su slogan en las elecciones de ese año: "nosotros estamos aquí; ellos, allî"; la izquierda israelí consideraba que lo que denominaban eufemísticamente "valla de separación" sería un paso para crear un Estado Palestino independiente, pues delimitaría sus futuras fronteras; pero, para Pappé (2002: 1), sólo era un paso más en el proceso iniciado en 1882 por el movimiento sionista para "desarabizar" Palestina -mediante la colonización, la expropiación y la expulsión- y borrarla del mapa.

Según Pappé (2002: 1, 3), en Oslo (1993) los palestinos aceptaron un mini-estado sobre el $22 \%$ de la Palestina del Mandato británico, es decir, dos territorios sin continuidad geográfica y a su vez divididos en cantones. Pero ni siquiera ese limitado proyecto se haría realidad, pues se diseccionaría en Áreas A, B, y C con distintos grados de reducida autonomía; la Franja de Gaza sería cerrada y rodeada por una valla electrificada como si de una gran cárcel se tratara -la misma situación en que ha quedado tras la retirada de Israel en agosto de 2005-; y el 42\% de Cisjordania y el 20\% de Gaza quedaría directa o indirectamente en manos israelíes.

La construcción del Muro propuesta por los laboristas la puso en marcha Sharon a fin de minar el Plan de Paz saudí de 2002 que contaba con el apoyo palestino y árabe. El Muro definiría la Palestina futura, que quedaría reducida al 75\% de Gaza y la mitad de Cisjordania, dividida a su vez en cantones aislados, y ambos territorios con una soberanía limitada apenas a dirigir los asuntos municipales.

Así, el Muro proyectado, que sigue construyendo Israel a pesar de todas las sentencia en su contra, supondría, según Pappé, que la población árabe autóctona quedaría encerrada en un área de menos del 15\% de la superficie original de Palestina, hasta que llegara el momento propicio para su expulsión definitiva. Pero, además, Pappé vaticinaba que el Muro sólo traería a Israel más violencia y aislamiento internacional, pues aislaría tanto a los palestinos como a los israelíes, aunque la peor parte sería para los palestinos, cuya infrahumana situación podría deteriorarse aún más si cabe, como de hecho está sucediendo.

Y todo esto lo ignoraba la población israelí, pues se le ocultaba dicha situación para alimentar su sensación de aislamiento y de estado de sitio a fin de que apoyaran las políticas intransigentes y agresivas de sus gobiernos. Pappé (2002: 4) denunciaba la cobardía de la prensa israelí, y en especial de los medios audiovisuales, que no informaban a la población de las circunstancias en que se producían los atentados: la ocupación, las humillaciones, los asesinatos, las detenciones masivas, la destrucción de hogares o el hambre que sufrían y sufren los palestinos y que alimentan los atentados suicidas, por lo que los israelíes aceptaban el Muro como si tuviera un poder mágico. 
Finalmente Pappé destacaba las represalias -o etiquetas de "antisemitas"- contra quienes osaban alzar la voz denunciando esa nueva catástrofe (Pappé, 2002: 2, 4-5).

\section{LA SENTENCIA DE LA HAYA EN LOS MEDIOS ESPAÑOLES}

El Tribunal Internacional de Justicia (TIJ) de La Haya emitió un fallo el 9 de julio de 2004 declarando ilegal el Muro de Cisjordania. Y los eficaces mecanismos de propaganda israelíes para manipular la información ${ }^{3}$ se activaron también para deslegitimar esa sentencia y luego para desviar la atención internacional hacia otras cuestiones.

Repasando una muestra de las noticias más significativas sobre el tema aparecidas en varios diarios españoles ${ }^{4}$-como El País, ABC, El Mundo, El Periódico de Cataliña o El Diario de Sevilla-, en la revista Tiempo, o en distintos informativos de televisión, se pueden extraer importantes conclusiones al respecto. Por ello nos centraremos en el análisis de la información ofrecida por esos medios desde el 24 de junio al 24 de julio de 2004, es decir, en un periodo de 15 días antes y después de producirse la sentencia del TIJ, para comprobar cómo evoluciona la información en torno a ella.

\section{1. Antes de la sentencia}

Desde el 11-S de 2001 la atención de los medios se focalizó, en general, en la llamada "guerra contra el terrorismo" que se estaba produciendo en Afganistán e Iraq, mientras quedaba desdibujada la durísima represión que sufría la población palestina bajo el gobierno de Ariel Sharon, "justificada" por su particular cruzada contra "el terrorismo" en los TTOO.

Por tanto, en el periodo previo al fallo del TIJ de La Haya, previsto para el 9 de julio de 2004, los medios focalizaban su atención en la guerra de Iraq, mientras se relegaba la situación de Palestina a un segundo plano informativo.

Y desde ese segundo plano, los medios informaban de la "muerte" de la "Hoja de Ruta" (El Mundo, 6-7-04) o de la preparación israelí de un nuevo "plan de paz" que tenía el visto bueno de EEUU, la UE y Egipto ( $A B C, 7-5-04)$, así como de las

\footnotetext{
${ }^{3}$ Entre los principales mecanismos de la "guerra israelí de la información", podemos destacar los siguientes: información a través de personas "creíbles", falseamiento de los datos, establecimiento de falsas simetrías, desinformación, focalización, simplificación y personalización del conflicto, deshumanización del enemigo, deslocalización y descontextualización del conflicto, negación de la realidad, limitación de la libertad de prensa, contraofensiva informativa o intimidación a los informadores no afines... (Cfr. Dray-Sieffert, 2004 y Thomas, 2007).

${ }^{4}$ Conste aquí nuestro agradecimiento al Dr. Esteban Arbués, profesor de la Universidad de Sevilla, y a la periodista sevillana Rocío Rubio Garrido, que nos han proporcionado parte de este material.
} 


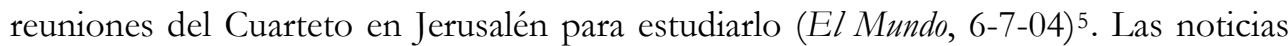
también se centraban en las críticas del Cuarteto a Arafat por "no abordar todas las reformas en materia de seguridad" (El Mundo, 8-7-04) y en las exigencias de Israel a la Autoridad Nacional Palestina para que controlase a los radicales, mientras el ejército israelí atacaba los campos de Gaza y anunciaba que permanecería en el norte de la Franja hasta el momento de retirarse (Diario de Sevilla, 3-7-04).

El plan de Sharon para la "Desconexión Unilateral de la Franja de Gaza" (aprobado el 6-6-04 y previsto para mediados de 2005) también acaparaba la atención de los medios, que señalaban sólo algunos de sus efectos (evacuación de unos 8.000 colonos), pero sin mencionar, por ejemplo, que suponía la ampliación de los asentamientos en Cisjordania; en esas informaciones se resaltaba, además, la crispación que dicho plan causaba en Israel y la probabilidad de que Sharon fuera asesinado por sus "concesiones" a los palestinos, como lo fue Rabin (4-11-1995) tras los Acuerdos de Oslo (El Mundo, 6/7-7-04), o el riesgo de caída de su gobierno (El Mundo, 7-7-04). Al tiempo, se insertaban breves noticias sobre el goteo ininterrumpido de palestinos "fallecidos" o "muertos" y de "ejecuciones extrajudiciales" -pocas veces llamadas "asesinatos selectivos"-, junto a noticias sobre israelíes "asesinados", sin señalar apenas las acciones de Israel que habían provocado los atentados palestinos en el eficaz recurso israelí de "provocación-represalia".

Bajo el titular de El Periódico de Cataluña "Ocho muertos en choques israelípalestinos" -que en realidad era una nueva incursión de Israel contra los campos de refugiados, con siete muertos palestinos ${ }^{6}$ y uno israelí-, un subtitular recogía la llegada a Israel de El Baradei, director del Organismo Internacional de la Energía Atómica,

\footnotetext{
5 El plan israelí, a grandes rasgos, constaba de VII puntos (cfr. $A B C, 7-5-04$, p. 28). Este "nuevo" plan era rechazado por los palestinos "radicales" que lo veían como un plan para romper la resistencia palestina y para ampliar los asentamientos de Cisjordania y acusaban a Egipto de velar más por la seguridad de Israel que por apoyar a los palestinos; pero en principio era "aceptado" por la Autoridad Nacional Palestina, aunque sólo en ciertos aspectos referidos al "plan de desconexión" de Gaza de Sharon, que no había sido negociado con los palestinos, $\mathrm{y}$ al proyecto de Mubarak para entrenar a sus servicios de seguridad; mientras, Israel exigía un control de la violencia que en la práctica se le negaba a Arafat al tenerlo aislado en la Muqata desde diciembre de 2001, al destruir sus infraestructuras, y al denegar en dicho plan aspectos fundamentales para el desarrollo normal de la vida palestina (Diario de Sevilla, 23-6-04; 24-6-04). También se destacaba el malestar europeo porque el propio Israel daba largas al plan "con la excusa de tener que hablar antes con Washington" (El Mundo, 8-7-04).

${ }^{6}$ Entre los muertos de ese día estaban Jaled Salah, profesor de la Facultad de Medicina de alNayah (Nablus), y su hijo de 16 años, que fueron asesinados en su propia casa; pero la versión israelí indicaba que murieron en el asedio a dos jefes locales del Frente para la Liberación de Palestina (El País, 7-7-04).
} 
"en una visita que no incluirá la central de Dimona"7; relegando el comentario al final de la noticia, se señalaba la intención de El Baradei de promover un Oriente Medio sin armas nucleares, aunque Israel no le permitiría visitar dicha central nuclear (El Periódico de Cataluña, 7-7-04), pues no era "asunto negociable porque no se puede reducir la seguridad de Israel mientras no exista un acuerdo global en la zona" (El Mundo, 8-704). ¡Y en otro titular suelto se informaba de la preocupación de EEUU e Israel "por el supuesto programa de armas nucleares de Irán" (El Periódico de Cataluña, 7-7-04)! Y pocos medios destacaban que Israel ponía "condiciones imposibles a un rápido desarme nuclear en la región” ( $A B C, 9-7-04)$.

Si ésas eran las noticias más destacadas en los medios, algunos de ellos informaban esos días, respecto al Muro, de la importante sentencia del Tribunal Supremo israelí (30-6-04) que ordenaba al gobierno modificar el trazado del Muro por "dañar los derechos de los palestinos", obligándole a "velar por las necesidades de la población local" 8 . Esta sentencia del Tribunal Supremo israelí respondía al recurso interpuesto por los palestinos porque el Muro afectaba a 35.000 palestinos, que quedaban "separados de sus cultivos, escuelas y trabajos". Para el gobierno israelí este fallo, que sentaba precedentes, causaba "un daño irreparable" a la seguridad de Israel, a pesar de que el Tribunal Supremo no prohibía su construcción. Para el abogado palestino Mohamed Dahla, "esta decisión es más importante que la de La Haya porque sí será acatada" (El Mundo, 30-6-04; Diario de Sevilla, 1-7-04), algo que luego se mostraría erróneo. Y raras veces se encontraba en la prensa la afirmación de Ahmed Qureia de que "no habrá paz mientras el Muro siga existiendo" (El Mundo, 8-7-04).

Al tiempo diversos informativos televisivos exhibían imágenes de las manifestaciones a favor de Israel que se producían frente al Tribunal de La Haya, incluidas las de un autobús reventado por un atentado palestino en Jerusalén, a fin de sensibilizar a la opinión pública y al TIJ de que la construcción del Muro estaba justificada por necesidades de autodefensa. Además en las televisiones proliferaron en esos días las películas sobre el holocausto.

\footnotetext{
7 Además de la central nuclear de Dimona hay otra en Najah Sorek, entre Jerusalén y Beer Sheva (El Mundo, 8-7-04). Pocas veces se señala que Israel es el único estado de la zona con capacidad nuclear, pues tiene cerca de 300 cabezas nucleares.

${ }^{8}$ Según Álvarez-Ossorio (2004: 5), el fallo que luego emitiría el TIJ de La Haya coincidía en parte con esta sentencia del Tribunal Supremo israelí al decir, por ejemplo, cosas como: el trazado del Muro a su paso por Jerusalén Este está provocando un "daño irreparable" a unos 35.000 palestinos al "recluirles en zonas aisladas de sus terrenos de cultivo, hospitales, escuelas y universidades"; "el trazado trastoca el delicado balance existente entre la obligación del mando militar de preservar la seguridad y su obligación de suplir las necesidades de los habitantes locales"; "la lucha del Estado contra el terrorismo debe conducirse dentro de los límites de la ley; el cumplimiento de la ley es un aspecto de la seguridad nacional: no hay seguridad sin ley".
} 
La prensa también destacaba que Sharon reafirmaba "su determinación de concluir el trazado del Muro, a pesar del inminente fallo del TIJ" (El Periódico de Cataluña, 4/57-04), fallo que podría tener importantes consecuencias políticas y jurídicas, aun no siendo vinculante. Y, al tiempo, ¡desaparecía de los titulares el fallo del Tribunal Supremo de Israel contra el trazado del Muro!

\section{2. El día de la sentencia del Tribunal Internacional de Justicia de La Haya (9-7-2004)}

El 9 de julio de 2004 el Tribunal Internacional de Justicia de la Haya dicta su fallo sobre el Muro de Cisjordania. Dada la extensión de la sentencia, nos vamos a limitar a exponer algunos de sus párrafos recogidos por Álvarez-Ossorio en un artículo publicado al poco tiempo de promulgarse ésta. El autor comienza señalando la poca disposición de Israel hacia una solución negociada de la cuestión palestina y el aceleramiento de la política de hechos consumados, tras el fracaso de Camp David (2000), para entorpecer la creación de un Estado Palestino viable. Esta política se basa en la colonización de los TTOO (donde viven 450.000 colonos israelíes), la judeización del Gran Jerusalén (que está dividiendo Cisjordania en dos partes) y la nacionalización de los recursos (incluida el agua, al quedar los asentamientos ilegales y los acuíferos del lado israelí tras la construcción del Muro que se comenzó a construir en el verano de 2002 y cuyo trazado definitivo no se había hecho público) (ÁlvarezOssorio, 2004: 1).

Tras algunas informaciones sobre objeciones al Muro anteriores a la sentencia, Álvarez-Ossorio analiza el fallo del TIJ titulado Las consecuencias legales de la construcción de la barrera en los territorios palestinos ocupados. En él se señala que se emite cumpliendo la "petición de la Asamblea General de la ONU" (Resolución ES-10/14 de 8-12-03) que requería una Opinión Consultiva del Tribunal, alarmada por "la confiscación y la destrucción de la tierra y los recursos palestinos, el trastorno de la vida de miles de civiles y la anexión de facto de extensas zonas de territorio" (Álvarez-Ossorio, 2004: 3).

Una vez afirmada la plena jurisdicción del TIJ para evaluar el caso, la sentencia respalda el derecho de autodeterminación de los palestinos y reclama la reanudación del proceso de paz con la puesta en marcha de la Hoja de Ruta, conforme a la Resolución 1515 del Consejo de Seguridad de la ONU (Álvarez-Ossorio, 2004: 3). Luego, el fallo del TIJ desestima el principal argumento israelí para construir el Muro, diciendo:

- "El TIJ no considera que el trazado que Israel ha elegido para el Muro sea el indicado para lograr sus objetivos de seguridad"; el Muro "infringe numerosos derechos de los palestinos que viven en el territorio ocupado por Israel, y las infracciones residen en que su trazado no puede justificarse por las exigencias militares o los requerimientos de seguridad u orden público" (Álvarez-Ossorio, 2004: 5). 
Álvarez-Ossorio (2004: 3-5) también recoge y analiza los fragmentos más significativos de la sentencia:

- "El Muro que está siendo erigido por Israel, la Potencia ocupante, en los Territorios Ocupados palestinos, incluido Jerusalén Este y sus alrededores, es contrario al Derecho internacional" (parr. 163, 3.A).

- "Israel está obligado a poner fin a sus incumplimientos del Derecho internacional; está obligado a interrumpir inmediatamente los trabajos de construcción del Muro que edifica en los Territorios Ocupados palestinos, incluida Jerusalén Este y sus alrededores, y a desmantelar de manera inmediata las estructuras allí establecidas" (parr. 163, 3.B).

- "Israel está obligado a reparar todos los daños causados por la construcción del Muro en los Territorios Ocupados palestinos, incluido Jerusalén Éste y sus alrededores" (parr. 163, 3.C).

- "Todos los Estados están en la obligación de no reconocer la situación ilegal resultante de la construcción del Muro y de no prestar ayuda o asistencia en el mantenimiento de la situación creada por esta construcción; todos los Estados partes de la Cuarta Convención de Ginebra relativa a la Protección de los Civiles en Época de Guerra del 12 de agosto de 1949 tienen, además, la obligación de asegurar el cumplimiento por parte de Israel del Derecho internacional humanitario (parr. 163. 3.D).

Y finalmente Álvarez-Ossorio (2004: 4) comenta esta última llamada del TIJ a la comunidad internacional, que viene justificada por la conculcación israelí de los derechos más elementales del pueblo palestino, como el derecho a la libertad de movimientos, a la propiedad, a la salud, a la educación, al trabajo, a la alimentación y a la libertad religiosa.

Como puede comprobarse, a pesar del limitado alcance de la sentencia del TIJ, se usa un léxico más correcto -aunque en el título denomina "barrera" al Muro-, se reconocen los derechos palestinos, en especial el derecho a la autodeterminación, y se denomina a Israel como "potencia ocupante".

Ese mismo día 9 de julio, la mayoría de los medios dan en sus ediciones on-line la noticia que luego recogerán sus ediciones impresas.

\section{3. El día siguiente de la sentencia (10-7-04)}

Al día siguiente de la sentencia del TIJ de La Haya, la mayoría de los medios dan la noticia en primera página y/o le dedican un editorial, aunque sólo pueden incluir unos pocos párrafos del fallo. Muchas noticias son de agencia, y por tanto ofrecen datos muy similares, aunque cada medio incide más en unos aspectos que en otros.

Tal vez el medio más significativo sea El País (10-7-04), que le dedica un titular en primera plana (p. 1), cinco crónicas (pp. 2 y 3) y un editorial (p. 12). El titular en portada dice: "El Tribunal de La Haya declara ilegal el Muro de Israel", y en el 
subtitular añade su petición de que se derribe. En la primera página comenta que el TIJ pide a Israel que devuelva a los palestinos la tierra confiscada para levantar el Muro e insta a la ONU a tomar medidas para acabar con la situación; o resalta que Israel anunció que no acataría el fallo y que los palestinos lo calificaron de victoria. Luego, en el texto de la noticia, resume los datos que ampliarán las cinco crónicas mencionadas: se refiere al proyecto de trazado de $730 \mathrm{~km}^{9}$ de Muro, de los que se han construido ya 196; a la indignación israelí porque el Tribunal ha olvidado "el terrorismo palestino" que lo justifica y a su afirmación de que la sentencia "acabará en el cubo de basura de la historia"; a la alegría palestina, que la califica de victoria; a la Comisión Europea, que comparte la sentencia, con la matización de Solana sobre el derecho de Israel a defenderse sin provocar "el indecible sufrimiento humano y económico" que causa a los palestinos; y al disgusto de EEUU que la calificó de "inapropiada".

En la crónica de Isabel Ferrer desde La Haya (El País, 10-7-04, p. 2), se glosan diversos detalles, como que, a instancias de la Asamblea General de la ONU, los 15 jueces del Tribunal emitieron un dictamen -por 14 votos a favor y uno, estadounidense, en contra- que fue filtrado horas antes a un diario israelí; y que dichos jueces justificaron su competencia para emitirla -contestada por Israel, EEUU y Rusiaen ser un órgano judicial de la ONU; luego incluye varios párrafos de la sentencia que dejan claro que el Muro no es el único modo que tiene Israel para defenderse de los ataques palestinos y que la "barrera" es ilegal porque "crea una anexión de hecho de territorio palestino" y viola la Convención de Ginebra de 1949, al privar a los palestinos de su derecho al trabajo, asistencia médica, educación y libertad de movimientos y sobre todo al impedirles "ejercer el derecho a la autodeterminación al aislarlos tras una pared sin justificación militar"; o que no es un "asunto bilateral entre Israel y Palestina", sino que "concierne a Naciones Unidas", recordando a ambas partes que han cometido actos ilegales y deben someterse al derecho internacional e instando a la comunidad internacional a no aceptar la situación ilegal creada por el Muro. La periodista destaca también las reacciones ante la sentencia: la Comisión Europea pide que se destruya la parte que ocupa suelo palestino; e Israel, al no ser vinculante, se apresura a declarar que no lo aceptará; también compara la pequeña manifestación de palestinos ante la sede del TIJ pidiendo la demolición del Muro, frente al despliegue hecho por Israel meses antes con la asistencia de cerca de 2000 personas para mostrar "el horror palestino y el rostro de sus casi mil víctimas" desde la segunda Intifada o los restos de un autobús destrozado en atentado del 19 de enero anterior.

Un despiece de I. F. [Isabel Ferrán] desde La Haya, titulado "La ONU recobra protagonismo" (El País, 10-7-04), aclara cuándo sus dictámenes son vinculantes o no, en cuyo caso su fuerza radica en la presión diplomática que puede ejercer; y señala que

9 Las cifras bailan de unas crónicas a otras en las diversas publicaciones. 
Sharon confía en que EEUU vete en el Consejo de Seguridad de la ONU cualquier resolución de condena a Israel por el Muro, mientras que Arafat espera que se sancione a Tel Aviv y se posibilite un Estado Palestino viable.

En otros dos despieces de El País (10-7-04) se añade un croquis del trazado del Muro y de su composición, explicando además ciertos detalles: su tamaño, fecha de inicio (agosto de 2002) y final previsto (finales de 2005) si no se interrumpen las obras con las demandas israelíes interpuestas tras el fallo del Tribunal Superior Israelí (junio 2004); también se describe en ellos la forma en que el Muro condicionará la vida de los 2 millones de palestinos de Cisjordania y en especial la de los 274.000 habitantes de los 122 pueblos y ciudades que quedarán emparedados entre el Muro y la frontera con Israel, que anexiona de facto entre el 45 y el $50 \%$ del territorio de Cisjordania, según la sentencia, aunque Israel dice que sólo será un 17\%; o que las puertas del Muro no sólo dificultan la libertad de movimientos palestinos sino que suponen un sofisticado sistema de control sujeto a la arbitrariedad israelí.

En la crónica de Ferrán Sales desde Jerusalén, titulada "Israel anuncia que no acatará el fallo y los palestinos lo consideran una victoria" (El País, 10-7-04, p. 3), se señala la indignación de los dirigentes de Israel que achacan la decisión a que procedía "de un conjunto de naciones de la Unión Europea que no son precisamente conocidas por su simpatía hacia Israel" y acusan a los miembros del TIJ de "negar a Israel el derecho a defenderse"; mientras, en los sectores israelíes moderados se aludía a que podrían negociar el trazado con los palestinos tras la retirada de Gaza a finales del 2005. También se refiere el periodista a la euforia de los palestinos ante la sentencia: Arafat la considera "una victoria de todo el pueblo" y de "todos los movimientos de liberación del mundo"; Ahmed Qureia dice que "se trataba de un día histórico", y Abu Rudeina habla de un principio de "aislamiento internacional de Israel". Finalmente alude a la intención palestina de llevar el tema a la Asamblea General y al Consejo de Seguridad de la ONU para que amenace a Israel con sanciones si no acata la sentencia de La Haya, o a que la población palestina la acoge con escepticismo, temiendo que se convierta en "papel mojado" como una anterior resolución de la Asamblea General de la ONU (Octubre de 2003) en el mismo sentido. Luego la crónica deriva hacia la intención de Sharon de formar un gobierno de unidad nacional con el Partido Laborista para salvar la situación y constata que el Muro se continuaba construyendo en dirección a los barrios árabes de Jerusalén Este. Y acaba refiriéndose a la posición de EEUU que consideraba que el tema debía resolverse en el cuadro de la aplicación de la Hoja de Ruta.

En una última crónica de El País $(10-7-04$, p. 3) se incide en el desacuerdo de EEUU con la sentencia frente al acuerdo de la UE que, aunque no se opone a la construcción del Muro, pide a Israel que desmantele los tramos que ocupan territorio palestino, pues dificultan la solución del conflicto.

Por último, el editorial de El País (10-7-04, p. 12) resume el significado de la sentencia y añade que el Muro se come el 16\% de los TTOO; también recuerda la 
anterior sentencia del Tribunal Supremo de Israel que exige la modificación del trazado; y pronostica que su no acatamiento perjudicará a la seguridad del propio Israel, para acabar diciendo que "el derecho internacional puede y debe proteger al Estado de Israel, a veces de sí mismo, como en el caso del Muro".

\section{4. Días posteriores a la sentencia}

Dos o tres días después del fallo, los medios comienzan a focalizar la información en el rechazo de los dirigentes de Israel a acatarlo, en sus acusaciones contra el TIJ y en la contraofensiva diplomática que emprenden contra el fallo. Y esa campaña se refuerza tras el atentado del 11 de julio en Tel Aviv que confirma su necesidad de proseguir la construcción del Muro.

Tras dicho atentado, El País (12-7-04) destaca en el titular de portada: "Sharon desafía a La Haya y ordena continuar la construcción del Muro", añadiendo en el subtitular que "El líder israelí acusa al tribunal de 'auspiciar' el último atentado". Pero, tras señalar que Sharon justifica su rechazo a la sentencia en su lucha contra el "terrorismo palestino", añade algo importante: "La Autoridad Palestina acogió con sospechas el ataque [atentado de Tel Aviv] y lo calificó de provocación". Y luego la atención se desvía hacia el tema de la negociación del gobierno israelí con los laboristas para formar un gobierno de unidad nacional.

Ferrán Sales, en su crónica desde Jerusalén (El País, 12-7-04, p. 2), se dedica a glosar el rechazo israelí al fallo, incluyendo algunas declaraciones de Sharon, que, además de acusar al TIJ de auspiciar el atentado, dice: "El Estado de Israel rechaza totalmente la opinión del Tribunal Internacional de Justicia. Se trata de una opinión unilateral detrás de la cual no hay más que consideraciones políticas. Esta opinión ignora totalmente la razón de la construcción de la barrera de seguridad, que no es más que el terrorismo palestino". También comenta el cambio de estrategia del gobierno israelí, que se había negado a comparecer ante el TIJ en marzo para defender su política "por no darles el gusto a los palestinos" y que ahora lanzaba a juristas y diplomáticos a "poner en marcha una guerra, con todos los medios a su alcance, contra la sentencia". Luego, en un despiece del mismo cronista se vuelve al tema del gobierno de unidad, matizando que "la hipotética coalición tendría una doble misión: llevar a término la descolonización de la Franja de Gaza y seducir a la comunidad internacional sobre la viabilidad del Muro" (El País, 12-7-04, p. 2). Y en otra crónica de Sandro Pozzi desde Nueva York, titulada "Annan exige a Israel que obedezca la ley internacional" (El País, 12-7-04, p. 2), el periodista comenta distintas declaraciones de otros representantes de la UE y Palestina en la ONU.

Por otro lado, la crónica de Javier Espinosa para El Mundo (12-7-04) se centra en describir con detalle el atentado de Tel Aviv del 11 de julio y la inmediata resolución de Sharon de proseguir la construcción del Muro, achacando el atentado al fallo de La Haya, que "envía un mensaje letal que anima el terror e impide protegerse contra él"; también incluye un comentario de dos diarios israelíes que admitían que la sentencia 
suponía un varapalo mayúsculo para la "imagen" del país, pues quedaba "retratado como un estado criminal que ha actuado en contra de la legislación internacional durante 37 años en los territorios palestinos"; esos comentarios incidían en que la resolución iba más allá del caso del Muro, pues desbarataba la posición israelí de que Cisjordania es un territorio "en disputa", y afirmaban que el estado judío "está implicado en una guerra de ocupación y anexión de territorios"; dichos diarios israelíes concluían diciendo: "La decisión de La Haya saca a Israel de la comunidad de países legales". Pero la crónica acaba con declaraciones de líderes palestinos, como las de Arafat y sus sospechas acerca de dicho atentado: "Estamos en contra de las bombas. Ustedes saben muy bien quién está detrás de estos actos. Lo saben Israel, los americanos y los europeos".

Otra crónica posterior de Javier Espinosa, titulada "Netanyahu vincula la resolución sobre el Muro al Holocausto" (El Mundo, 16-7-04), es muy sintomática de la ofensiva emprendida por la diplomacia israelí para defender el Muro. La crónica recoge, entre otras cosas, declaraciones israelíes como: "La sentencia de La Haya ha conseguido que la historia se repita dos veces; (...) primero fue la tragedia, la muerte de seis millones de judíos en Europa (...); ustedes [los europeos] no levantaron un dedo mientras mi gente era masacrada (...); y ahora se produce la farsa, cuando la Corte Internacional de La Haya asegura que Israel no tiene derecho a defenderse del terrorismo"; o "La barrera es enormemente efectiva (...) y funciona"-se incluyen las cifras que da el ministro de Seguridad-. Y cuando el periodista le recuerda a Netanyahu el impacto devastador que el Muro tiene sobre los palestinos, éste declara: "El principio de seguridad tiene limites (...); de hecho no utilizamos todo nuestro poder de fuego [contra los milicianos palestinos]. Respondemos de una manera mesurada. Sí, a veces se producen bajas civiles, pero ésas son consecuencias trágicas que conlleva toda guerra. No atacamos deliberadamente a los civiles como hacen los terroristas. Sí, algunos niños palestinos llegan tarde a la escuela [por el Muro], pero nuestros hijos no llegan a veces nunca. Estamos hablando de la eliminación de familias enteras (...$)$, de atentados en hoteles, discotecas, restaurantes"; $y$, tras asegurar que van a facilitar la vida a los palestinos con nuevos túneles y carreteras, Netanyahu concluye diciendo: "Esta resolución ha causado daño a la guerra contra el terror (...), y ha dañado el proceso de paz (....) y la futura resolución política del conflicto, porque el liderazgo palestino se crecerá".

En esos días posteriores a la sentencia del TIJ también saltan a la prensa noticias sobre el crecimiento del antisemitismo en Francia, por ejemplo con un titular como éste: "La brutal agresión antisemita a una mujer desata la alarma en Francia" (Diario de Sevilla, 12-7-04); o señalando la "indignación de Francia" por la llamada de Sharon a los judíos franceses para que se instalen en Israel huyendo del antisemitismo reinante (ABC, 20-7-04; Diario de Sevilla, 20-7-04), situación descrita como "guerra civil fría" entre judíos y musulmanes en Francia ( $A B C, 21-7-04)$. Según Le Monde, las declaraciones de Sharon pretenden dejar en EEUU e Israel la imagen de que hay "un país antisemita en el corazón de Europa" -en referencia a Francia-, intentando así 
eliminar a Europa del juego político en Oriente Medio, por su política pro-árabe, y dejarla sólo en su papel de banquero (El País, 22-7-04). Y este mismo medio incluye un artículo de Glucksman sobre "Las fuentes del antisemitismo francés" (El País, 227-04) y un comentario a dicho artículo de Haro Teglen (El País, 23-7-04).

A partir de entonces los distintos medios van a desviar la atención de la sentencia del TIJ para focalizarla en la necesidad de llegar a un "gobierno de unidad" en Israel, poniendo de relieve las disputas internas del Likud y la amenaza de Sharon de convocar elecciones anticipadas (El Mundo, 13/14-7-04; ABC, 13-7-04; Diario de Sevilla, 13-7-04).

También aparecen de forma dispersa noticias sobre críticas a Israel de algún gobierno árabe; sobre una posible amenaza de la UE de suspender el acuerdo de asociación con Israel si no acata la sentencia; sobre la intención palestina de convocar urgentemente la Asamblea General de la ONU para debatir el fallo del TIJ y exigir a Israel que lo acate (El Mundo,13-7-04); o sobre la decisión de Israel de modificar el trazado de acuerdo con la sentencia de su propio Tribunal Supremo, no a causa del fallo de La Haya (Diario de Sevilla, 14-7-04).

Al tiempo, se repiten con profusión noticias sobre atentados y secuestros palestinos, mientras son escasas las noticias sobre algunas muertes o "decesos" de palestinos -aunque según el Diario de Sevilla (17-7-04) son 3.183, frente a 929 israelíes desde la Intifada del 2000-, destacando sólo algunas muertes llamativas, como la de un anciano palestino aplastado en su domicilio de Gaza por las excavadoras israelíes ( $E l$ Mundo,13-7-04; ABC, 13-7-04; Diario de Sevilla, 13-7-04). Y otros medios señalan que "Los palestinos declaran persona 'non grata' al enviado de la ONU", Roed-Larsen, por afirmar que "la falta de voluntad política" de Arafat ha hecho que la situación se haya deteriorado progresivamente en los TTOO hasta llegar al caos, o que Arafat no ha dado un apoyo claro a las iniciativas de paz y sólo las respalda de una forma "simbólica y parcial" ( $A B C, 15-7-04)$, focalizando así la atención pública en Arafat, a quien se responsabiliza de la dramática situación en que viven los palestinos.

A partir del 16 de julio comienza a aparecer en los medios el debate iniciado en la Asamblea General de la ONU -cuyas resoluciones no son vinculantes al contrario de las del Consejo de Seguridad- sobre el fallo del TIJ. Se señala la esperanza palestina de que la comunidad internacional haga frente común contra la "valla" que los aísla en una "serie de bantustanes", y las palabras del embajador israelí ante la ONU sobre la "dura batalla" que presentaría Israel frente a la "mayoría inmoral" que "en la Asamblea General tienen los países árabes y musulmanes, así como cierto número de estados no democráticos" (Diario de Sevilla, 17-7-04). Además se destaca el tenso debate entre los miembros de la Asamblea General de la ONU sobre su posible resolución, como la crónica "Otra brecha en 'el Muro' de la ONU”, donde el embajador israelí dice: "Los locos se han hecho con el control del manicomio" en referencia a la crisis de la Autoridad Nacional Palestina. Tras el 20 de julio, varios medios recogen también que la Asamblea General de la ONU ha aprobado "por 
abrumadora mayoría" -150 votos contra 6, entre ellos EEUU- una Resolución que exigía el cumplimiento del dictamen judicial de La Haya (El Mundo, 21-7-04; Diario de Sevilla, 22-7-04), pero que Israel proseguiría con el Muro pese a esa nueva resolución (El País, 22-7-04). También se informa de que Israel reprocha a la UE su "apoyo vergonzoso" a esa Resolución de la Asamblea General de la ONU (El Mundo, 22-7-04; Diario de Sevilla, 23-7-04).

Luego, a partir del 20 de julio, la atención de los medios se focalizará en el debate sobre el "plan de desconexión de Gaza" y en la declaración de Sharon sobre dicho plan: "No podremos mantener el carácter judío y democrático del Estado si continuamos reinando sobre un millón de palestinos"; pero otro medio señala que la razón de esta declaración era que, como los judíos iban a quedar pronto en minoría frente a los palestinos, Israel debía renunciar a los asentamientos en Gaza para conservar y reforzar los de Cisjordania (Diario de Sevilla, 17-7-04).

Finalmente, la atención de los medios acabará por focalizarse en los enfrentamientos internos palestinos, calificando la situación de caos (ElMundo, 20/217-04; ABC, 20-7-04; Diario de Sevilla, 19/22-7-04), achacando la crisis a "la parálisis de Arafat" ( $A B C, 21-7-04)$-que estaba cercado en la Mukata-, señalando que el Parlamento palestino exigía a Arafat reformas inmediatas (El País, 22-7-04), y resaltando la toma de dicho Parlamento por rebeldes palestinos (El País, 23-7-04).

\section{ConCLUSIÓN}

Para cualquier persona interesada por lo que ocurre en el mundo, ha sido difícil comprender en todas sus dimensiones la trascendencia de la construcción del "Muro del Apartheid", como ya se le denomina, y las sentencias en su contra. Sólo recabando noticias de gran número de medios, el lector interesado podía hacerse una idea algo más completa de la cuestión. ¡Y cuánto más problemático se le presentaba al resto de la opinión pública!

Por un lado, muchas de las noticias sobre el tema son de agencia, por lo que están dominadas por pautas venidas de fuera, lo que limita la libertad de expresión de los periodistas o articulistas. Por otro, cada medio proporciona sólo algunos datos, por lo que es difícil conocer la realidad en su conjunto, lo que produce una importante distorsión de los hechos.

Los medios escritos de mayor audiencia han transmitido la noticia de la sentencia de La Haya, pero dejando abundantes lagunas de información y sin hacer la menor crítica a la propia sentencia por emplear el término "barrera" para lo que es un "Muro" de 8 a 12 metros de alto que domina toda Cisjordania; o recalcando las falsas simetrías entre las actuaciones israelíes y palestinas y dando mayor protagonismo a la indignación de Israel y su rechazo a la sentencia. Por otro lado, muchos titulares no reflejan los múltiples matices que a veces se incluyen en el texto de la crónica, y que a menudo los contradicen, dejando una falsa idea en quien sólo lea el titular. 
Tras conocer el fallo del TIJ, muchos medios se hacen amplio eco de la contracampaña diplomática, jurídica e informativa que pone en marcha Israel para contrarrestar los efectos negativos de todas las sentencias emitidas contra el Muro. Y en esa campaña se destaca su intento de deslegitimar al TIJ y a quienes han apoyado el fallo de La Haya o la posterior resolución de la Asamblea General de la ONU, así como la defensa a ultranza de EEUU a las posturas israelíes, con su deslegitimación de las resoluciones de la ONU y de la ley internacional, algo que Israel comparte con EEUU.

Tanto antes como después de la sentencia también se advierte una intensa focalización informativa hacia otros temas distintos del Muro, pero es más llamativa tras la sentencia del TIJ, con lo que pronto desaparecen de las primeras planas las sentencias del Tribunal Superior de Israel y el fallo del Tribunal de Justicia de la Haya, dando prioridad a la propuesta de un gobierno de unidad en Israel o a los "desesperados" intentos de Sharon por retirarse de Gaza y al caos en que está sumida la sociedad palestina. Además, al tratar del "plan de paz" israelí o su "plan de desconexión de Gaza", se deja una sensación de "generosidad" israelí -resaltando que incluso ponen en riesgo la vida del propio Sharon-, frente a la postura "inflexible" de Arafat y los palestinos, presentados a menudo como "terroristas" y "radicales" incapaces de aceptar tan generosas ofertas.

Además hay que destacar el modo en que la política informativa israelí recurre a recordar el Holocausto y a acusar de "antisemitismo" a cualquiera que critique su política, deslocalizando así el conflicto político que se produce en Palestina y justificando la necesidad de los judíos de tener un estado en el que protegerse de los ataques antisemitas.

Por último hay que señalar que, en poco tiempo, las noticias sobre las sentencias contra el muro y la dramática situación de los palestinos quedarán oscurecidas por la atención preferente de los medios a la guerra de Iraq, a cuya sombra Israel proseguirá su particular guerra contra los palestinos en general y contra Arafat en especial.

\section{REFERENCIAS BIBLIOGRÁFICAS}

Álvarez-Ossorio Alvariño, I., "El Muro de separación y el futuro de Palestina”. Real Instituto Elcano de Estudios Internacionales y Estratégicos. Art $\mathrm{n}^{\circ}$ 126, 2004:6 $<$ http://www.realinstitutoelcano.org/analisis/556.asp>

Dray, J. y Sieffert, Y., La guerra israeli de la información. Desinformación y falsas simetrías en el conflicto palestino-israelí. Trad. de Fernando García Burillo. Guadarrama (Madrid) Ediciones del Oriente y del Mediterráneo, 2004.

Pappé, I., "El Muro en el corazón de Palestina". Trad. de CSCA web. Al-Ahram Weekly Online, 11/17 de Julio, 2002:5

$<$ http://joc.es/csca/palestina/pappe_6-08-02.html>

El-Sarraj, E., "Descansen en paz", 2004.

$<$ http://www.alqudsmalaga.org/articulos.php>. 
Thomas de Antonio, C. M., "El conflicto de Palestina y la política informativa israelî". Idearabia, $\mathrm{n}^{\circ}$ 6, 2007 (en prensa).

Clara $\mathrm{M}^{\mathrm{a}}$ Thomas de Antonio

cthomas@siff.us.es

Fecha de recepción: 27 de febrero de 2007

Fecha de aceptación: 4 de junio de 2007

Dpto. de Filologías Integradas.

Área de Estudios Árabes e Islámicos.

Facultad de Filología

C/ Palos de la Frontera s.n.

41004 Sevilla. 